\section{A COMPUTERIZED CONTROL SYSTEM FOR CARDIOPULMONARY BYPASS}

A pump control system using a microcomputer for cardiopulmonary bypass has been developed. The parameters monitored by the computer are central venous pressure, aortic pressure, blood volume in a reservoir, and collapsing of a small vinyl bag in a venous withdrawal tube. Both pumps in the arterial infusion and the venous withdrawal lines are automatically controlled through an interface unit throughout cardiopulmonary bypass. The system regulates central venous pressure with a proportional-integral control algorithm to maintain intravascular volume constant. A screening algorithm is devised to remove artifacts introduced to the pressure measurement. During the weaning period, a perfusionist can select either the central venous pressure control or a reservoir blood volume control. Computerized pump perfusion was applied on 15 children during cardiac operations. Perfusion flow and central venous pressure were controlled satisfactorily with stable operation. Compared with conventional manually controlled pump perfusion, no significant difference was noted in mean aortic pressure, central venous pressure, net fluid balance, total urination, blood chemistry, and urinalysis. This system is useful and is expected to improve the safety of pump perfusion. ( $J$ THORAC Cardiovasc Surg 1995;109:428-38)

Toshiyuki Beppu, $\mathrm{ME},{ }^{\mathrm{a}}$ Yasuharu Imai, $\mathrm{MD},{ }^{\mathrm{a}}$ and Yasuhiro Fukui, $\mathrm{PhD},{ }^{\mathrm{b}}$ Tokyo, Japan
$S^{\text {in }}$ ince the first successful cardiac operation with cardiopulmonary bypass (CPB) was performed by Gibbon, ${ }^{1}$ the heart-lung machine has been improved almost to perfection for clinical use. Although improvements in hardware of the pumpoxygenator in the past 40 years have been remarkable, the actual mode of operation of the device has remained unchanged. A perfusionist is still forced to monitor a blood level in a reservoir and blood pressures continuously to adjust the perfusion rate throughout CPB. Regulation of pump perfusion causes few problems for adult patients having a large intravascular volume. However, for patients in the newborn period or in early infancy weighing 3 to $4 \mathrm{~kg}$, maintaining the blood balance is difficult. Further-

\footnotetext{
From the Department of Pediatric Cardiovascular Surgery, The Heart Institute of Japan, Tokyo Women's Medical College, ${ }^{\mathrm{a}}$ and the Department of Applied Electronic Engineering, Tokyo Denki University, ${ }^{b}$ Tokyo, Japan.

Supported in part by Grant-in-Aid for Scientific Research from the Ministry of Education, Science, and Culture of Japan.

Received for publication Dec. 23, 1993.

Accepted for publication June 16, 1994.

Address for reprints: Toshiyuki Beppu, ME, The Heart Institute of Japan, Tokyo Women's Medical College, 8-1 Kawadacho Shinjuku-ku, Tokyo 162 , Japan.

Copyright (C) 1995 by Mosby-Year Book, Inc.

$0022-5223 / 95 \$ 3.00+0 \quad \mathbf{1 2} / \mathbf{1} / \mathbf{5 8 4 2 0}$
}

more, during prolonged perfusion, the danger of human errors resulting from fatigue or a lack of attentiveness exists. Nevertheless, no safety devices are incorporated in current heart-lung machines, for instance, to detect an imbalance in flow or continuously monitor changes in blood level in the reservoir. The need for bloodless prime and reduction in the priming volume is ever increasing because of the need to prevent blood-borne infections. Downsizing of the CPB circuit, however, has to be backed up by a proper computer control technology. With the aim of improving the safety of CPB, attempts have been made to automate the heart-lung machine, ${ }^{2-8}$ but these modifications are not used in clinical practice. The purpose of this study is to improve the safety of CPB to cope with the future needs for straight hemodilution and to maintain proper blood balance in infants and neonates. ${ }^{9-11}$ Since 1982 we have been developing an automated CPB system. Its safety and performance were tested through extensive experiments in 50 mongrel dogs. We started applying this system clinically in 1990. The present article reports a newly developed computerized $\mathrm{CPB}$ system and verifies its control ability.

\section{Materials and methods}

Computerized CPB system. The computerized CPB system consists of an 80286 microcomputer (PC9801RA, 


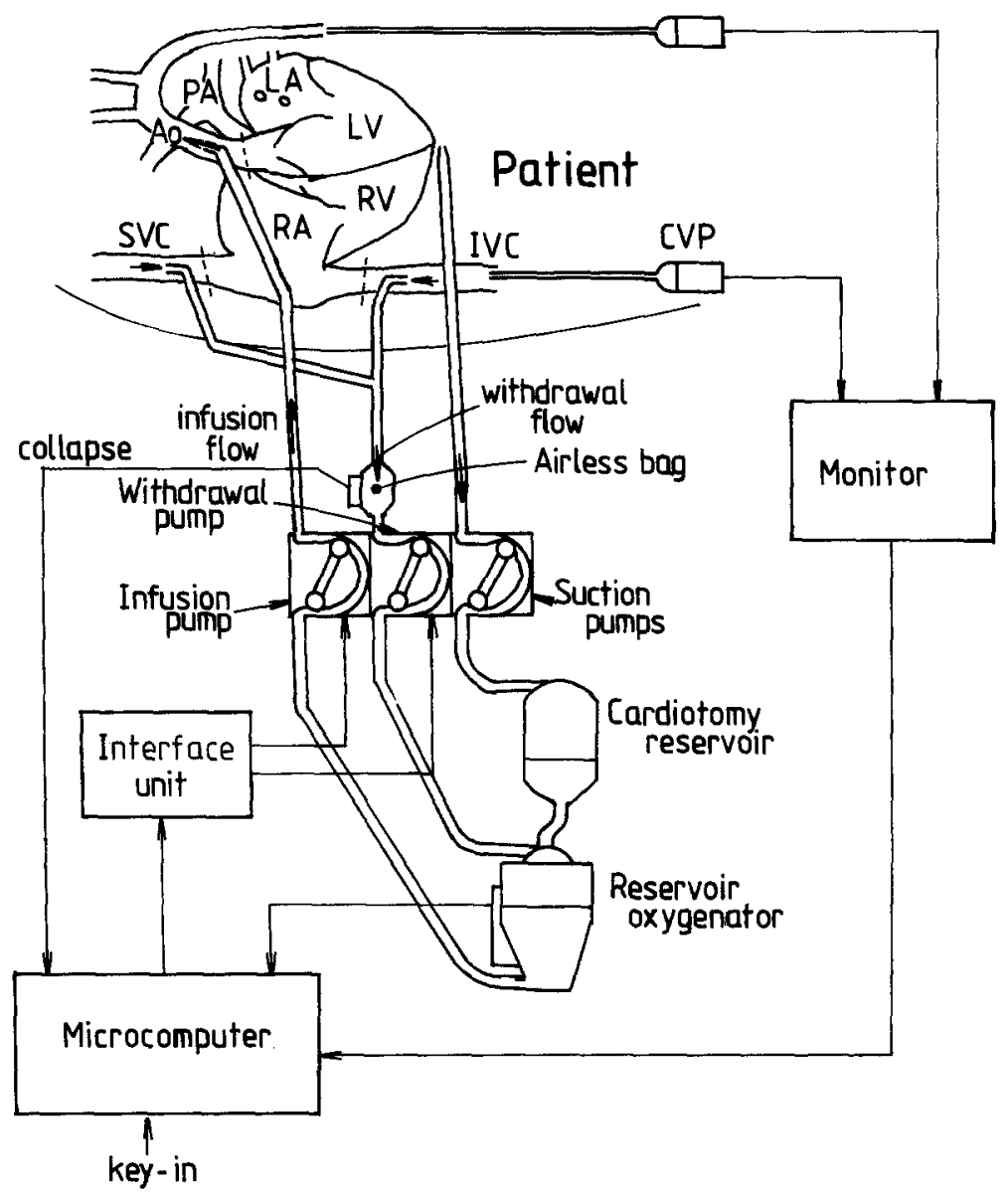

Fig. 1. Schematic diagram of a computerized CPB system. $P A$, Pulmonary artery; $L A$, left atrium; $L V$, left ventricle; $R A$, right atrium; $R V$, right ventricle; $S V C$, superior vena cava; $I V C$, inferior vena cava; $C V P$, central venous pressure; $A \circ P$, aortic pressure.

NEC Corp., Tokyo, Japan), a pulsatile infusion pump, a venous withdrawal pump (PS $\alpha-120$ or PS $\alpha-150$, Tonokura-Ikakogyo Corp., Tokyo, Japan), a reservoir blood level sensor, and a collapse sensor (Fig. 1). The collapse sensor, comprising a set of photoelectric switches (E3CJC4, OMRON Corp., Osaka, Japan) attached to both sides of a small vinyl bag in a venous withdrawal tube (airless bag), detects the collapse of the venae cavae caused by excessive blood withdrawal. Sixty-two photoelectric sensors (P1241, Hamamatsu-Hotonikusu Corp., Shizuoka, Japan), placed in two lines at a distance of 2.54 $\mathrm{mm}$, are installed on the side of a reservoir incorporated in the oxygenator to measure blood quantity with a resolution of approximately $30 \mathrm{ml}$ (reservoir level sensor). Central venous pressure (CVP) and aortic pressure (AoP) are monitored by diaphragm transducers (DX-360, ViggoSpectramed Corp., Singapore). The computer samples AoP, CVP, reservoir blood volume, and collapse of the airless bag with an eight-channel twelve-bit A/D converter (Analog-Pro 1, Canopus Corp., Kobe, Japan) at intervals of 0.1 second. The computer controls both infusion and withdrawal pumps through an interface unit (Interface- box, Tonokura-Ikakogyo Corp.) by an eight-bit parallel interface.

Computer control algorithms. At the beginning of $\mathrm{CPB}$, the computer is programmed to keep a positive blood balance for a patient by administering a small amount of blood to him to minimize the initial fall in aortic pressure. Therefore, the computer starts both infusion and withdrawal pumps at rates of 12 and $6 \mathrm{ml} / \mathrm{min}$ per kilogram, respectively, and then gradually increases the flow rate to attain the preset perfusion flow rate of 80 $\mathrm{ml} / \mathrm{min}$ per kilogram within a minute. The computer keeps the infusion flow rate at $80 \mathrm{ml} / \mathrm{min}$ per kilogram and regulates CVP to maintain the circulating blood volume of a patient constant by adjusting the venous withdrawal flow rate. When a perfusionist keys in a new perfusion flow set point, the computer adjusts the infusion flow rate to the new set point and alters the withdrawal flow in the same rate.

A proportional-integral control algorithm with a control interval of 1 second was adopted for the CVP controller (Fig. 2). The CVP set point value is initially settled by the computer to the average preceding the 


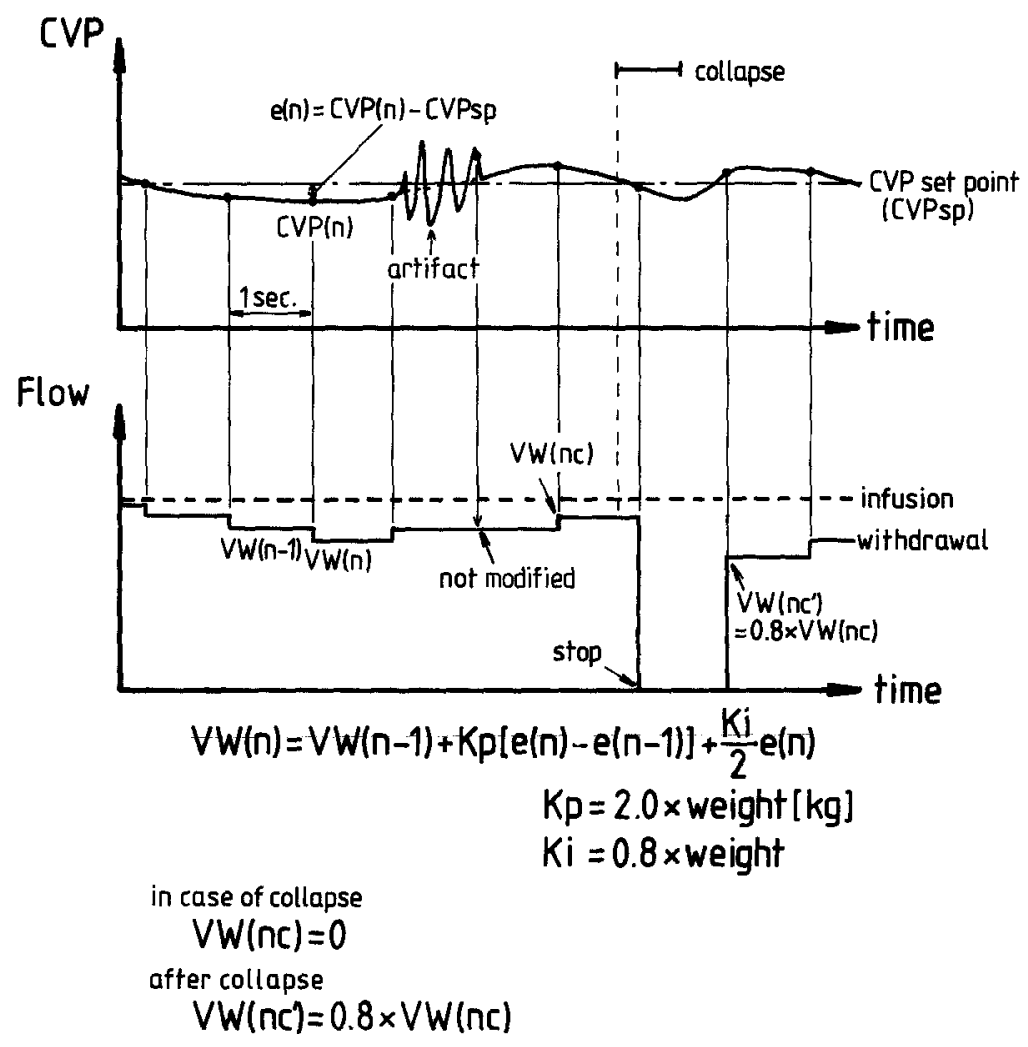

Fig. 2. The venous withdrawal flow control method of the computerized CPB system. Venous withdrawal flow at time $n[V W(n)]$ is calculated from an error between CVP and the CVP set point at the time $[e(n)]$, at the preceding time $[e(n-1)]$, and the flow rate before the control time. When an artificial noise is measured on the CVP measurement, the computer holds the venous flow rate constant. At a moment of collapsing of the venae cavae $[V W(n c)]$, the computer stops the venous flow and restarts with a reduced rate $\left[V W\left(n c^{\prime}\right)\right]$.

cannulation. Later the CVP set point and the perfusion flow set point may be changed by the computer automatically or by the perfusionist through a keyboard at any time.

The computer stops the withdrawal pump immediately when the veins are collapsed. After resumption of filling of the airless bag, the computer restarts blood withdrawal at a reduced flow rate, $80 \%$ of the value preceding the collapse, to minimize repetition of the collapse. Venous collapses usually disappear by this means of control within 1 second in the majority of cases. In case of continual collapsing, the arterial infusion pump is programmed to slow down and then to halt within 10 seconds. To avoid a vicious cycle of repetition of collapsing, the computer is programmed to increase the CVP set point if two other collapses recur within a minute. During the collapse, temporary cessation of venous withdrawal may elevate CVP by 1 or $2 \mathrm{~cm} \mathrm{H}_{2} \mathrm{O}$. Hence the CVP control after a collapse will increase the withdrawal flow rate and this may cause another collapse. This collapse control takes precedence over the CVP control.

When the amount of blood in the reservoir falls below the warning level of $230 \mathrm{ml}$, the computer reduces both infusion and withdrawal flow rates to $80 \%$. If the blood level remains below the warning level for 10 seconds, the computer reduces the current CVP set point temporarily to the withdrawal of blood from the patient to the reservoir. The moment the reservoir blood level falls below the minimum value of $180 \mathrm{ml}$, both pumps automatically stop to avoid air embolism. Immediately after the reservoir blood level rises above the minimum, the computer restarts both pumps at the reduced rate of $80 \%$. If the blood volume rises above the warning level, the computer increases the flow rates to $100 \%$. The reservoir minimum volume control has priority over the CVP and the collapse control.

In the weaning period, the perfusionist inspects pressures and the action of the patient's heart and then keys in a decreased set point for the perfusion flow. The computer maintains the infusion flow rate above the set point. At this period, a perfusionist can select a reservoir control mode instead of the CVP mode. The proportional-integral control algorithm was also adopted for the reservoir controller. The computer controls CVP or the reservoir volume until the pump stops.

Artifact detection and handling. During CPB, the CVP measurement is interfered with by several kinds of artificial noise. Surgical manipulation, suturing the right atrium, lift- 
Table I. Clinical characteristics of patients

\begin{tabular}{|c|c|c|c|c|c|c|}
\hline & \multicolumn{3}{|c|}{ Ventricular septal defect } & \multicolumn{3}{|c|}{ Tetralogy of Fallot } \\
\hline & $\begin{array}{l}\text { Computer control } \\
\quad(n=8)\end{array}$ & $\begin{array}{l}\text { Manual control } \\
\quad(n=8)\end{array}$ & $p$ Value & $\begin{array}{l}\text { Computer control } \\
\quad(n=7)\end{array}$ & $\begin{array}{l}\text { Manula control } \\
\quad(n=7)\end{array}$ & $p$ Value \\
\hline Age (years) & $0.8 \pm 0.7$ & $1.0 \pm 1.1$ & NS & $3.1 \pm 2.6$ & $2.1 \pm 1.6$ & NS \\
\hline Body weight (kg) & $7.3 \pm 2.1$ & $8.2 \pm 1.9$ & NS & $12.7 \pm 4.0$ & $11.4 \pm 2.7$ & NS \\
\hline Body surface area $\left(\mathrm{m}^{2}\right)$ & $0.37 \pm 0.08$ & $0.39 \pm 0.08$ & NS & $0.54 \pm 0.14$ & $0.51 \pm 0.11$ & NS \\
\hline \multicolumn{7}{|l|}{ CTR $(\%)$} \\
\hline Before operation & $61.8 \pm 3.0$ & $61.5 \pm 3.5$ & NS & $54.9 \pm 4.3$ & $51.0 \pm 3.5$ & NS \\
\hline After operation & $58.6 \pm 4.0$ & $60.4 \pm 3.7$ & NS & $60.1 \pm 5.2$ & $56.7 \pm 2.0$ & NS \\
\hline $\begin{array}{l}\text { PA index } \\
\quad(\text { normal value } 330 \pm 30)\end{array}$ & & & & $211 \pm 28$ & $283 \pm 117$ & NS \\
\hline LVEDV (\% of normal) & & & & $122 \pm 33$ & $113 \pm 23$ & NS \\
\hline RVEDV (\% of normal) & & & & $121 \pm 32$ & $115 \pm 17$ & NS \\
\hline \multicolumn{7}{|l|}{ Associated anomalies } \\
\hline Aortic regurgitation & 2 & 0 & & 0 & 0 & \\
\hline Atrial septal defect & 1 & 0 & & 0 & 1 & \\
\hline Mitral regurgitation & 1 & 3 & & 0 & 0 & \\
\hline Persistent ductus arteriosus & 0 & 0 & & 2 & 0 & \\
\hline Persistent foramen ovale & 3 & 3 & & 4 & 4 & \\
\hline Persistent left SVC & 2 & 0 & & 0 & 0 & \\
\hline Pulmonary atresia & 0 & 0 & & 1 & 0 & \\
\hline (post B-T shunt) & 0 & 0 & & 3 & 0 & \\
\hline
\end{tabular}

NS, Not significant, $C T R$, cardiothoracic ratio, $P A$, pulmonary artery, $L V E D V$, left ventricular end-diastolic volume, $R V E D V$, right ventricular end-diastolic volume, $S V C$, superior vena cava, $B-T$, Blalock-Taussig.

ing up the heart, and other maneuvers make noises that interfere with the measurement. The maneuvers to evacuate air on completion of the intracardiac repair, such as inflation of the lungs, particularly modulate CVP. Flushing the catheter or checking the transducer zero balance alters the measurements expeditiously. A small artificial CVP change does not affect the computer control, but a large artifact might cause a dangerous flow change.

We designed on-line screening algorithms to prevent artifacts from changing the flow rates. A screening algorithm monitors the intensity of the frequency spectrum above $2 \mathrm{~Hz}$. When the intensity exceeds three times the average, the program presumes that the change in CVP is an artifact. Because the usual CVP measurement has no frequency spectrum above $2 \mathrm{~Hz}$ under general anesthesia, however, the artificial fluctuation in CVP is usually associated with the high-frequency spectrum. Another screening algorithm catches the change in CVP over $2 \mathrm{~cm} \mathrm{H}_{2} \mathrm{O}$ per 1 second, because these rapid changes are mostly caused by surgical manipulation. When a shift in CVP value into a range between -0.5 and $0.5 \mathrm{~cm} \mathrm{H}_{2} \mathrm{O}$ after the rapid change occurs, the computer regards it as the zero balance check of the transducer. At the moment of and 2 seconds after detection of the artifact, the computer interrupts, changing both the flow rates and holding them constant.

Safety mechanisms. The computer regularly verifies all samples with their prior values and detects not only artifacts but also hardware failures. On detecting the improper sensor output, the computer maintains both the flow rates constant and displays a warning message with estimated locations of the trouble. The pump rotation speeds are also monitored and matched with the computer's command. The computer stops both the pumps on detection of pump failure. The computer detects the air intake into the venous line or a loose occlusion of the venous pump by comparing CVP and the withdrawal pump rate. The computer alerts the perfusionist in case the mean withdrawal flow rate of the preceding $10 \mathrm{~min}$ utes drops under the predetermined rate of $80 \mathrm{ml} / \mathrm{min}$ per kilogram, the average AoP exceeds $80 \mathrm{~mm} \mathrm{Hg}$, and repeated collapses of the venae cavae are detected.

In case the computer breaks down, a perfusionist can take over the pump control by turning an automatic/ manual switch to the manual mode. On the contrary, the computer is able to resume the pump control from manual mode by switching it back to the automatic mode at any time. The computer then keeps the flow rate and CVP to the average.

Patients and clinical protocols. Thirty patients were scheduled for intracardiac repair after written informed consent by their parents had been obtained. They were divided into two groups. Computerized CPB was applied in one group of 15 patients, and conventional manually controlled CPB was used in another group of 15 patients. Eight of the patients in each group had ventricular septal defect (VSD) and seven of them had tetralogy of Fallot (TOF). No significant differences were noted between the groups with regard to age, body weight, body surface area, cardiothoracic ratio, pulmonary artery index (cross-sectional area of the pulmonary artery [square millimeter] body surface area [square meter]), ${ }^{12}$ and left ventricular and right ventricular end-diastolic volume in the TOF group (Table I). All the CPBs were performed by the same pump system. A VP-CML membrane oxygenator (Cobe Laboratories Inc., Lakewood, Colo.) or a D705 Midflo hollow-fiber oxygenator (Dideco Corp., Mirandola, Italy) was used for the CPB. 
Table II. The change of CVP during computer-controlled $C P B$

\begin{tabular}{|c|c|c|c|c|c|c|c|c|c|c|c|c|c|c|}
\hline \multicolumn{5}{|c|}{ Patients } & \multicolumn{2}{|c|}{ Time (min) } & \multicolumn{6}{|c|}{ Initial $C V P s p-C V P_{s p}\left(\mathrm{~cm} \mathrm{H}_{2} \mathrm{O}\right)$} & \multirow{2}{*}{$\begin{array}{c}\text { Duration } \\
\text { of } \\
\text { normal } \\
(\%)\end{array}$} & \multirow{2}{*}{$\begin{array}{c}\text { Total } \\
\text { balance } \\
(\mathrm{ml} / \mathrm{kg})\end{array}$} \\
\hline No. & Age & $\operatorname{Sex}$ & $\begin{array}{l}\text { Weight } \\
\text { (kg) }\end{array}$ & $\begin{array}{l}B S A \\
\left(m^{2}\right)\end{array}$ & Bypass & Clamp & $\begin{array}{c}+5 \\
\min \end{array}$ & Clamp & $\begin{array}{l}+30 \\
\min \end{array}$ & $\begin{array}{l}+60 \\
\min \end{array}$ & Unclamp & Post-CPB & & \\
\hline \multicolumn{15}{|c|}{ Ventricular septal defect } \\
\hline 1 & $9 \mathrm{mo}$ & Male & 7.1 & 0.36 & 84 & 61 & $-1^{*}$ & \pm 0 & \pm 0 & \pm 0 & \pm 0 & +2 & 96.2 & +4.8 \\
\hline 2 & $1 \mathrm{yr}$ & Male & 9.5 & 0.45 & 133 & 86 & $-4 \dagger$ & -4 & -4 & -4 & -4 & -4 & 93.4 & -9.5 \\
\hline 3 & $1 \mathrm{yr}$ & Male & 7.7 & 0.40 & 76 & 44 & \pm 0 & $-4 \ddagger$ & -3 & & -4 & +2 & 89.9 & +9.7 \\
\hline 4 & $4 \mathrm{mo}$ & Female & 5.0 & 0.27 & 93 & 74 & \pm 0 & \pm 0 & \pm 0 & \pm 0 & \pm 0 & -4 & 95.3 & -13.8 \\
\hline 5 & $1 \mathrm{yr}$ & Male & 9.5 & 0.46 & 70 & 33 & \pm 0 & \pm 0 & \pm 0 & & \pm 0 & +1 & 94.5 & -12.9 \\
\hline 6 & $2 \mathrm{yr}$ & Male & 9.3 & 0.43 & 118 & 75 & \pm 0 & $+2 \|$ & +6 & +8 & +8 & +8 & 90.0 & +8.9 \\
\hline 7 & $5 \mathrm{mo}$ & Female & 4.2 & 0.24 & 86 & 50 & \pm 0 & $+2 \|$ & +4 & & +4 & +3 & 64.4 & -9.4 \\
\hline 8 & $10 \mathrm{mo}$ & Female & 6.4 & 0.35 & 116 & 73 & \pm 0 & $+2 \|$ & +8 & +10 & +10 & +5 & 85.5 & +46.8 \\
\hline Mean & & & & & & & & & & & & & $88.7 \pm 9.7$ & $3.1 \pm 18.9$ \\
\hline \multicolumn{15}{|c|}{ Tetralogy of Fallot } \\
\hline 9 & $2 \mathrm{yr}$ & Male & 12.3 & 0.52 & 213 & 71 & \pm 0 & \pm 0 & -1 & +1 & \pm 0 & \pm 0 & 96.2 & +8.9 \\
\hline 10 & $6 \mathrm{yr}$ & Male & 14.0 & 0.62 & 143 & 63 & \pm 0 & \pm 0 & \pm 0 & \pm 0 & \pm 0 & +2 & 98.6 & +1.7 \\
\hline 11 & $1 \mathrm{yr}$ & Female & 7.5 & 0.38 & 133 & 56 & \pm 0 & $-2 \$$ & $+2 \|$ & & +2 & +6 & 99.3 & +25.7 \\
\hline 12 & $2 \mathrm{yr}$ & Female & 11.4 & 0.50 & 138 & 71 & $-2 \S$ & \pm 0 & $-3 \div$ & -5 & -6 & +3 & 96.1 & +24.3 \\
\hline 13 & $4 \mathrm{yr}$ & Female & 16.5 & 0.67 & 153 & 76 & \pm 0 & +1 & $+2 \|$ & +1 & +3 & +2 & 96.0 & 11.2 \\
\hline 14 & $7 \mathrm{yr}$ & Male & 18.5 & 0.76 & 115 & 65 & \pm 0 & $-3^{*} \ddagger$ & $+2 \|$ & -4 & -4 & \pm 0 & 98.8 & +17.5 \\
\hline 15 & $11 \mathrm{mo}$ & Female & 8.8 & 0.40 & 196 & 88 & $-5^{*}$ & -2 & -2 & -2 & -2 & +7 & 93.1 & +33.9 \\
\hline Mean & & & & & & & & & & & & & $96.9 \pm 2.0$ & $17.6 \pm 10.3$ \\
\hline $\begin{array}{l}\text { Correlation } \\
\text { coefficient }\end{array}$ & & & & & & & & 0.02 & 0.20 & 0.33 & 0.21 & 0.64 & & \\
\hline$p$ Value & & & & & & & & NS & NS & NS & NS & 0.008 & & \\
\hline
\end{tabular}

CVPSp, CVP set point; $B S A$, body surface area; clamp, aortic crossclamping; $+5 \mathrm{~min}$, five minutes from the CPB start; +30 min, thirty minutes from aortic crossclamping; +60 min, sixty minutes from aortic crossclamping; unclamp, at removal of aortic crossclamp; post-CPB, CVP on completion of CPB; duration of normal, duration of the error between CVP and the CVP set point was smaller than $2 \mathrm{~cm} \mathrm{H}_{2} \mathrm{O}$; correlation coefficient, correlation coefficient of CVP and total balance; $N S$, not significant.

${ }^{*} \mathrm{CVP}$ was lowered because of bleeding.

$\dagger C V P$ was lowered because of an inappropriate initial set point value.

$\ddagger$ CVP was lowered intentionally.

\$CVP was lowered because the amount of blood in a reservoir fell below the warning level.

|iCVP was increased because of repetitive collapses.

All patients received routine premedication, consisting of diazepam $1 \mathrm{mg} / \mathrm{kg}$ orally 1 hour before the operation, pethidine hydrochloride $1 \mathrm{mg} / \mathrm{kg}$ orally, and scopolamine $0.018 \mathrm{mg} / \mathrm{kg}$ intramuscularly. Anesthesia was induced with morphine 1 to $2 \mathrm{mg} / \mathrm{kg}$, and pancuronium $2 \mathrm{mg}$ was used as a muscle relaxant. After intubation, the lungs were ventilated with oxygen and room air to maintain eucapnia. Either 16-gauge or 18-gauge catheters (Safuro, Terumo Corp., Tokyo, Japan) were introduced into the inferior vena cava and the descending aorta via the femoral artery and vein. The heart was exposed through a standard median sternotomy. A Tonokura $2.3 \mathrm{~mm}$ cannula (Tonokura-Ikakogyo Corp.) for patients weighing less than $5 \mathrm{~kg}$ and a Sarns high-flow aortic arch cannula, $3.8 \mathrm{~mm}$ (Sarns Inc./3M, Ann Arbor, Mich.), for those weighing more than $5 \mathrm{~kg}$ was used for the ascending aortic cannulation. The superior vena cava and the inferior vena cava were cannulated with two straight cannulas (14F to $20 \mathrm{~F}$, William Harvey arterial perfusion cannulas, C. R. Bard, Inc., Billerica, Mass.). A blood prime to maintain a hematocrit value of more than $20 \%$ during the perfusion was adopted for the CPB circuit. Ringer's lactate solution was added to obtain appropriate hemodilution. Heparin sodium $2 \mathrm{ml}$, $8.4 \%$ sodium bicarbonate $20 \mathrm{ml}$, and pancuronium $2 \mathrm{ml}$ were also added into the circuit. Moderate hypothermia with a rectal temperature ranging from $26^{\circ}$ to $28^{\circ} \mathrm{C}$ was used during CPB. Perfusion flow rates were settled 80 to $120 \mathrm{ml} / \mathrm{min}$ per kilogram, which is equivalent to 2.0 to 2.2 $\mathrm{L} /$ min per square meter. Low arterial pressure (20 to 40 $\mathrm{mm} \mathrm{Hg}$ ) during aortic cross-clamping was left uncorrected and mean $\mathrm{AoP}$ over $80 \mathrm{~mm} \mathrm{Hg}$ was controlled by intravenous nitroglycerin.

Blood chemistry tests were performed a few days before and on the first day after the operation. Total protein, aspartate aminotransferase, alanine aminotransferase, lactic dehydrogenase, urea nitrogen, creatinine, and platelet count were analyzed with a Hitachi 7450 analyzer (Hitachi Corp., Tokyo, Japan). Postoperative alveolararterial oxygen difference was measured and urinary free hemoglobin, protein, and sugar were checked with $\mathrm{He}$ mateslax-3 test paper (Miles-Sankyo Corp., Tokyo, Japan) immediately after the operation. These results obtained by test paper were graded as follows: minus as one, plus-minus as two, plus as three, two-plus as four, and 

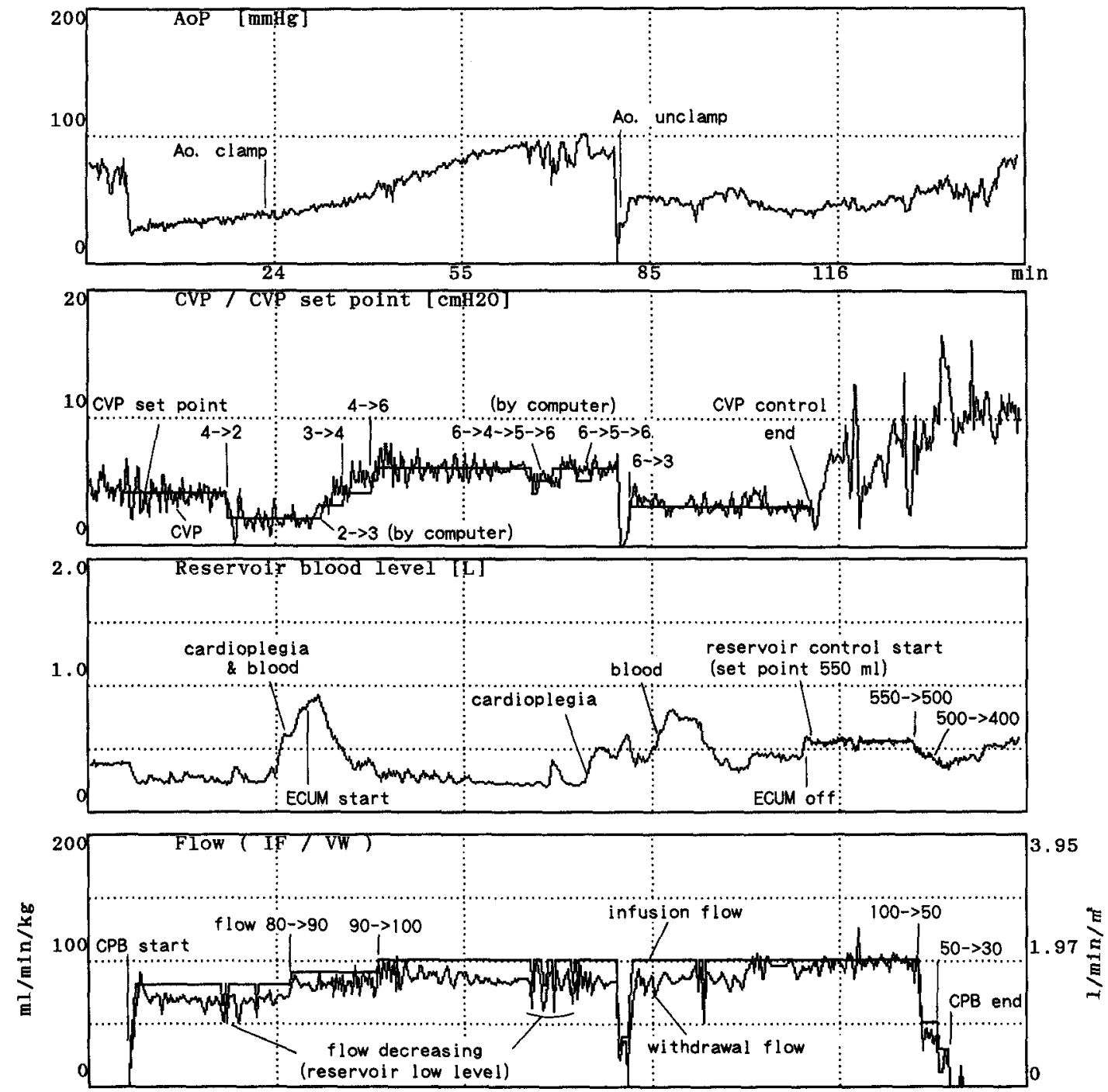

Fig. 3. Hemodynamic recordings during computerized CPB (patient 11, female, 1 year, $7.5 \mathrm{~kg}, 0.38 \mathrm{~m}^{2}$, tetralogy of Fallot). From top, the tracings show AoP, CVP, and the CVP set point, reservoir blood volume, and infusion flow $(I F)$ and venous withdrawal flow $(V W), E C U M$, Extracorporeal membrane filtration.

three-plus as five. Amount of postoperative blood transfusion and durations of continuous infusion of isoproterenol and dopamine were observed.

Statistical analysis. The SAS program (SAS Institute Inc., Cary, N.C.) was used for statistical analysis. Values are presented as mean \pm standard deviation and are compared by Student's $t$ test. Differences were considered significant if $p$ was less than 0.05 .

\section{Results}

The computerized CPB system was able to regulate CVP in the range between $\pm 2 \mathrm{~cm} \mathrm{H}_{2} \mathrm{O}$ of the set point in $88.7 \% \pm 9.7 \%$ of CPB time in the VSD group and in $96.9 \% \pm 2.0 \%$ in the TOF group (Table II).
The CVP set point had to be reset manually or automatically in five patients (Nos. 6, 7, 8, 11, and 13) because the initial CVP set point made repetitive collapsing of the venae cavae. The total fluid balance during computerized CPB was within the range of mean \pm 2 standard deviation of the manually controlled group (VSD, $+2.0 \pm 23.3 \mathrm{ml} / \mathrm{kg}$; TOF, +11.0 $\pm 11.7 \mathrm{ml} / \mathrm{kg}$ ). The total fluid balance was closely correlated with CVP value on completion of CPB $(0.64 ; p=0.008)$. However, it had no correlation with CVP set points during CPB. The initial CVP set point that was the average CVP preceding the cannulation was appropriate except in patient 2 , in whom the CVP 

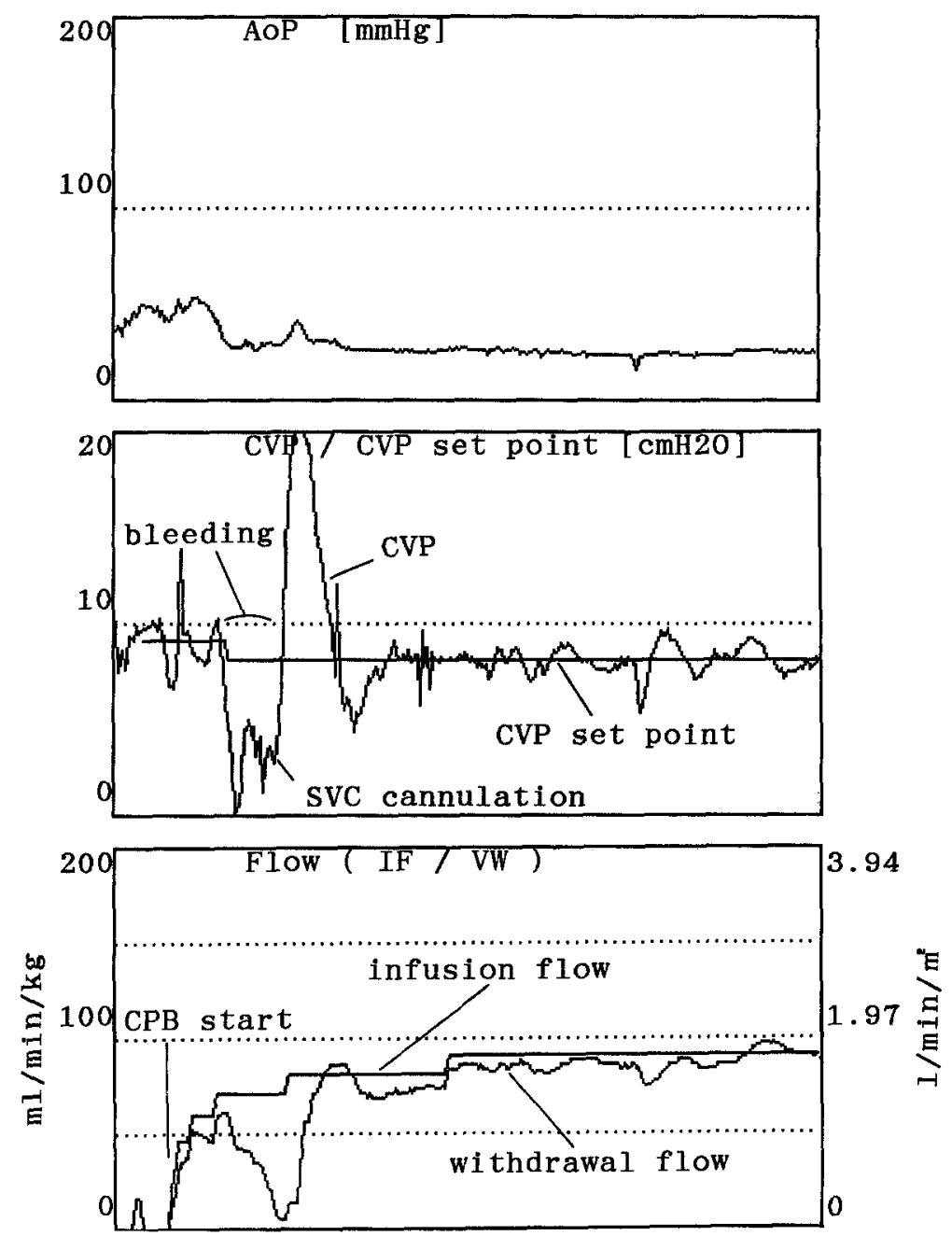

Fig. 4. Recordings of perfusion pressures and the flow rates at the onset of computerized CPB (patient 1, male, 9 months, $7.1 \mathrm{~kg}, 0.36 \mathrm{~m}^{2}$ ). $S V C$, Superior vena cava; $I F$, infusion flow; $V W$, venous withdrawal flow.

set point was lowered immediately after the onset of CPB because CVP was high during manipulations for cannulation. We changed the CVP set point until 5 minutes from the start of CPB in three other patients because of bleeding into the surgical field (Nos. 1 and 15) or because of a low blood level in the reservoir (No. 12).

Perfusion pressures, flow rates, and reservoir blood volumes during computerized CPB are shown in Fig. 3. At the onset of CPB, on command from a perfusionist, the computer started both infusion and withdrawal pumps and then increased both pump rates to the total flow rate of $80 \mathrm{ml} / \mathrm{min}$ per kilogram (1.6 $\mathrm{L} / \mathrm{min}$ per square meter) with 40 seconds. The computer adjusted the withdrawal flow rate to keep CVP to the initial set point of $4 \mathrm{~cm} \mathrm{H}_{2} \mathrm{O}$. At 16 minutes from the start of $\mathrm{CPB}$, the computer de- creased both infusion and withdrawal flow rates temporally because the reservoir blood level dropped under the warning level. The perfusionist noticed a message of low reservoir level on the display and changed the CVP set point from 4 to 2 $\mathrm{cm} \mathrm{H}_{2} \mathrm{O}$. At 23 minutes, the aorta was crossclamped. Then the perfusionist raised the flow set point to 90 $\mathrm{ml} /$ min per kilogram $(1.8 \mathrm{~L} / \mathrm{min}$ per square meter), because the computer displayed a message of shortage of perfusion flow. At the same instant, $150 \mathrm{ml}$ of cardioplegic solution was injected and $400 \mathrm{ml}$ of blood was transfused because the hematocrit value was $17 \%$. The amount of reservoir blood was rapidly elevated from 250 to $900 \mathrm{ml}$ and then lowered to 300 $\mathrm{ml}$ within 6 minutes by extracorporeal ultramembrane filtration. The CVP set point was increased by the computer at 31 minutes and by the perfusionist 


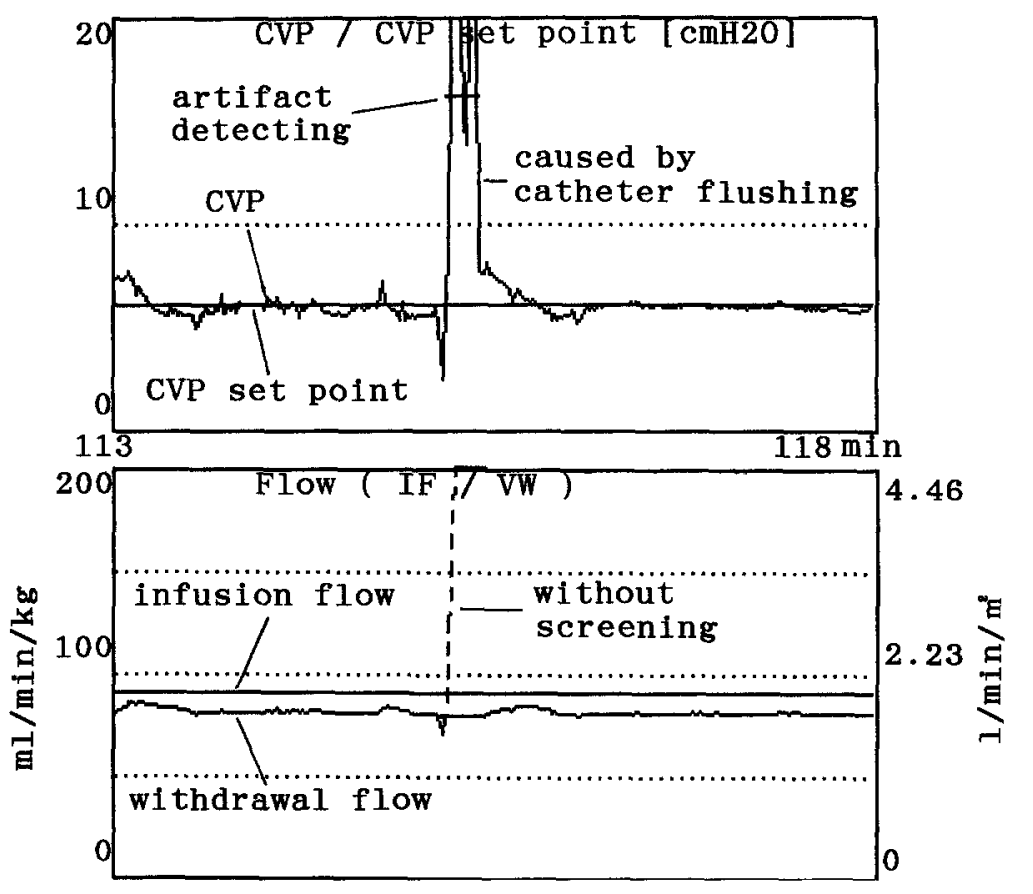

Fig. 5. Recordings of venous pressure and flow rates with artificial fluctuations on the venous pressure measurement (patient 9, male, 2 years, $12.3 \mathrm{~kg}, 0.52 \mathrm{~m}^{2}$ ). A dashed line on the flow graph showed a virtual response of the venous flow without the screening. $I F$, Infusion flow; $V W$, venous withdrawal flow.

at 34 minutes, because of several episodes of caval collapse. At 40 minutes, the computer displayed the message of shortage of perfusion flow. Then the perfusionist changed the perfusion flow set point to $100 \mathrm{ml} / \mathrm{min}$ per kilogram $(2.0 \mathrm{~L} / \mathrm{min}$ per square meter) and modified the CVP set point to $6 \mathrm{~cm} \mathrm{H}_{2} \mathrm{O}$ because the increased flow caused repetitive collapses. After that, the computer maintained CVP to the set point adequately. At around 65 and 73 minutes, the computer reduced perfusion flow rates and lowered the CVP set point transiently as a result of low reservoir level. At 79 minutes, the perfusionist altered the flow set point to $20 \mathrm{ml} / \mathrm{min}$ per kilogram $(0.4 \mathrm{~L} / \mathrm{min}$ per square meter $)$ temporally in preparation for aortic unclamping. After the aorta was unclamped, the computer restored the perfusion flow rate to $100 \mathrm{ml} / \mathrm{min}$ per kilogram $(2.0 \mathrm{~L} / \mathrm{min}$ per square meter) with a command key-in. The CVP set point was lowered to $3 \mathrm{~cm} \mathrm{H}_{2} \mathrm{O}$, because the venous return increased after the aorta was unclamped. At 100 minutes, bleeding from the right ventricular incision ceased on completion of the outflow tract reconstruction; hence the flow difference between the infusion and the withdrawal disappeared. At 110 minutes, the perfusionist switched the control mode from the CVP to the reservoir.
The reservoir blood volume was regulated stably, yet CVP fluctuations were appreciably increased. Near the termination of $\mathrm{CPB}$, the perfusionist lowered the reservoir set point by stages from 550 to $400 \mathrm{ml}$ and reduced the perfusion flow set point from 100 to $30 \mathrm{ml} / \mathrm{min}$ per kilogram $(0.6 \mathrm{~L} / \mathrm{min}$ per square meter) and finally zero. Shortly after the command key-in, the computer stopped both pumps.

A response to unexpected bleeding is shown in Fig. 4. In this case, shortly after cannulation of the inferior vena cava, the surgeon commanded the $\mathrm{CPB}$ to start. The perfusionist limited the perfusion flow set point to $70 \mathrm{ml} / \mathrm{min}$ per kilogram $(1.4 \mathrm{~L} / \mathrm{min}$ per square meter), waiting for complete filling of the airless bag. The right atrial incision caused massive bleeding, which rapidly lowered the CVP from 9 to $1 \mathrm{~cm} \mathrm{H}_{2} \mathrm{O}$. The computer reduced the withdrawal flow rate to recover CVP. After bleeding was controlled by cannulation of the superior vena cava, the computer followed the CVP elevation and increased the revolution speed of the venous pump CVP was stabilized around the set point of $8 \mathrm{~cm} \mathrm{H}_{2} \mathrm{O}$ within 1 minute.

A trend graph of an episode of CVP fluctuations caused by flushing the venous catheter is shown in Fig. 5. A sign on the upper graph registered the 
Table III. $C P B$ data

\begin{tabular}{|c|c|c|c|c|c|c|}
\hline & \multicolumn{3}{|c|}{ Ventricular septal defect } & \multicolumn{3}{|c|}{ Tetralogy of Fallot } \\
\hline & $\begin{array}{c}\text { Computer } \\
\text { control } \\
(n=8)\end{array}$ & $\begin{array}{c}\text { Manual } \\
\text { control } \\
(n=8)\end{array}$ & $\begin{array}{c}p \\
\text { Value }\end{array}$ & $\begin{array}{c}\text { Computer } \\
\text { control } \\
(n=7)\end{array}$ & $\begin{array}{c}\text { Manual } \\
\text { control } \\
(n=7)\end{array}$ & $\begin{array}{c}p \\
\text { Value }\end{array}$ \\
\hline Bypass time (min) & $97.0 \pm 22.6$ & $123.5 \pm 24.3$ & 0.041 & $155.9 \pm 35.5$ & $151.6 \pm 21.1$ & NS \\
\hline Crossclamp time (min) & $62.4 \pm 18.5$ & $66.8 \pm 17.8$ & NS & $70.0 \pm 10.3$ & $76.7 \pm 14.1$ & NS \\
\hline Total balance (ml/kg/per hour) & $+1.15 \pm 10.73$ & $+1.05 \pm 9.72$ & NS & $+7.04 \pm 4.08$ & $+4.75 \pm 4.88$ & NS \\
\hline Urination (ml/kg per hour) & $0.81 \pm 1.16$ & $2.65 \pm 2.51$ & NS & $2.47 \pm 1.78$ & $1.71 \pm 1.40$ & NS \\
\hline $\mathrm{Aa} \mathrm{PO}_{2}$ gradient $(\mathrm{mm} \mathrm{Hg})$ & $234.4 \pm 143.6$ & $191.0 \pm 153.5$ & NS & $89.0 \pm 23.4$ & $110.7 \pm 41.8$ & NS \\
\hline Urinary free hemoglobin & $1.5 \pm 1.1$ & $2.0 \pm 1.4$ & NS & $3.3 \pm 1.7$ & $3.4 \pm 2.0$ & NS \\
\hline Urinary protein & $1.8 \pm 0.9$ & $2.2 \pm 0.7$ & NS & $2.9 \pm 1.2$ & $2.3 \pm 0.8$ & NS \\
\hline Urinary sugar & $2.0 \pm 1.3$ & $2.5 \pm 1.5$ & NS & $1.7 \pm 1.0$ & $2.6 \pm 1.5$ & NS \\
\hline Blood transfusion (ml) & $73.4 \pm 55.3$ & $121.9 \pm 97.2$ & NS & $191.1 \pm 224.1$ & $226.1 \pm 196.7$ & NS \\
\hline Duration of ISP (day) & $3.1 \pm 2.5$ & $3.0 \pm 4.2$ & NS & $7.1 \pm 3.4$ & $4.9 \pm 3.0$ & NS \\
\hline Duration of DOA (day) & $2.3 \pm 1.2$ & $1.9 \pm 1.7$ & NS & $4.1 \pm 2.5$ & $5.3 \pm 3.5$ & NS \\
\hline \multicolumn{7}{|l|}{ Blood biochemistry tests } \\
\hline \multicolumn{7}{|c|}{ Total protein (normal range $6.5-8.2 \mathrm{gm} / \mathrm{dl}$ ) } \\
\hline Before operation & $6.66 \pm 0.21$ & $6.98 \pm 0.53$ & NS & $7.04 \pm 0.36$ & $6.93 \pm 0.52$ & NS \\
\hline After operation & $5.91 \pm 0.25$ & $6.25 \pm 0.67$ & NS & $6.34 \pm 0.51$ & $6.33 \pm 0.60$ & NS \\
\hline \multicolumn{7}{|l|}{ AST (normal range $6-25 \mathrm{KU}$ ) } \\
\hline Before operation & $28.9 \pm 6.1$ & $30.5 \pm 7.5$ & NS & $24.0 \pm 4.4$ & $25.4 \pm 4.8$ & NS \\
\hline After operation & $115.9 \pm 35.4$ & $57.0 \pm 93.5$ & NS & $156.7 \pm 19.4$ & $135.1 \pm 43.4$ & NS \\
\hline \multicolumn{7}{|l|}{ ALT (normal range 0-19 KU) } \\
\hline Before operation & $12.4 \pm 5.7$ & $9.6 \pm 4.8$ & NS & $7.9 \pm 2.5$ & $10.3 \pm 4.8$ & NS \\
\hline After operation & $13.1 \pm 4.9$ & $13.3 \pm 4.6$ & NS & $14.4 \pm 2.5$ & $14.6 \pm 2.9$ & NS \\
\hline \multicolumn{7}{|c|}{$\mathrm{LDH}$ (normal range $100-250 \mathrm{mU} / \mathrm{dl}$ ) } \\
\hline Before operation & $305.9 \pm 48.1$ & $338.8 \pm 76.8$ & NS & $306.7 \pm 42.8$ & $311.4 \pm 36.9$ & NS \\
\hline After operation & $743.0 \pm 98.7$ & $848.6 \pm 286.2$ & NS & $948.1 \pm 85.0$ & $886.4 \pm 126.3$ & NS \\
\hline \multicolumn{7}{|c|}{ Urea nitrogen (normal range $8-20 \mathrm{mg} / \mathrm{dl}$ ) } \\
\hline Before operation & $13.25 \pm 4.46$ & $13.74 \pm 5.07$ & NS & $13.30 \pm 2.53$ & $13.72 \pm 2.10$ & NS \\
\hline After operation & $15.19 \pm 3.19$ & $15.29 \pm 5.42$ & NS & $16.31 \pm 3.06$ & $14.74 \pm 2.27$ & NS \\
\hline \multicolumn{7}{|c|}{ Creatinine (normal range $0.7-1.3 \mathrm{mg} / \mathrm{dl}$ ) } \\
\hline Before operation & $0.26 \pm 0.09$ & $0.31 \pm 0.06$ & NS & $0.37 \pm 0.13$ & $0.37 \pm 0.08$ & NS \\
\hline After operation & $0.33 \pm 0.09$ & $0.36 \pm 0.07$ & NS & $0.43 \pm 0.10$ & $0.43 \pm 0.08$ & NS \\
\hline \multicolumn{7}{|c|}{ Platelet count (normal range $15-35 \cdot 10^{4} / \mathrm{mm}^{2}$ ) } \\
\hline Before operation & $32.6 \pm 9.9$ & $32.2 \pm 10.2$ & NS & $24.6 \pm 7.6$ & $35.7 \pm 14.0$ & NS \\
\hline After operation & $10.2 \pm 4.2$ & $8.9 \pm 1.7$ & NS & $6.5 \pm 7.6$ & $6.9 \pm 4.2$ & NS \\
\hline
\end{tabular}

$N S$, Not significant, $A a P_{2}$ alveolar-arterial oxygen tension; ISP, isoproterenol; $D O A$, dopamine; $A S T$, aspartate aminotransferase, $A L T$, alanine aminotransferase, $L D H$, lactate dehydrogenase.

period that the screening algorithm regarded the change of CVP measurement as an artifact. While detecting the artifact, the computer kept the venous flow rate constant. The dashed line on the lower graph, which was a virtual response of the withdrawal flow rate without the screening algorithm, indicated an excessive increase.

Similar results were obtained in patients with conventional manually controlled $\mathrm{CPB}$ and those with computer-controlled CPB (Table III). There were no deaths and there was no need for assisted circulation or reoperation in our study population. In the VSD group, the mean CPB perfusion time of the computer-controlled group was significantly shorter than that of the manually controlled group
$(97.0 \pm 22.6$ minutes versus $123.5 \pm 24.3$ minutes, $p=0.041$ ). Mean perfusion time in the TOF group, myocardial ischemic time, total fluid balance, and amount of urine excretion during CPB were not significantly different in the two groups. Alveolararterial oxygen tension difference and a urine test (free hemoglobin, protein, and sugar) at the end of $\mathrm{CPB}$, amount of postoperative blood transfusion, and duration of continuous infusion of isoproterenol and dopamine were not significantly different. Blood chemistry results before and after operation (total protein, aspartate aminotransferase, alanine aminotransferase, lactic dehydrogenase, urea nitrogen, creatinine, and platelet count) showed no significant differences. 


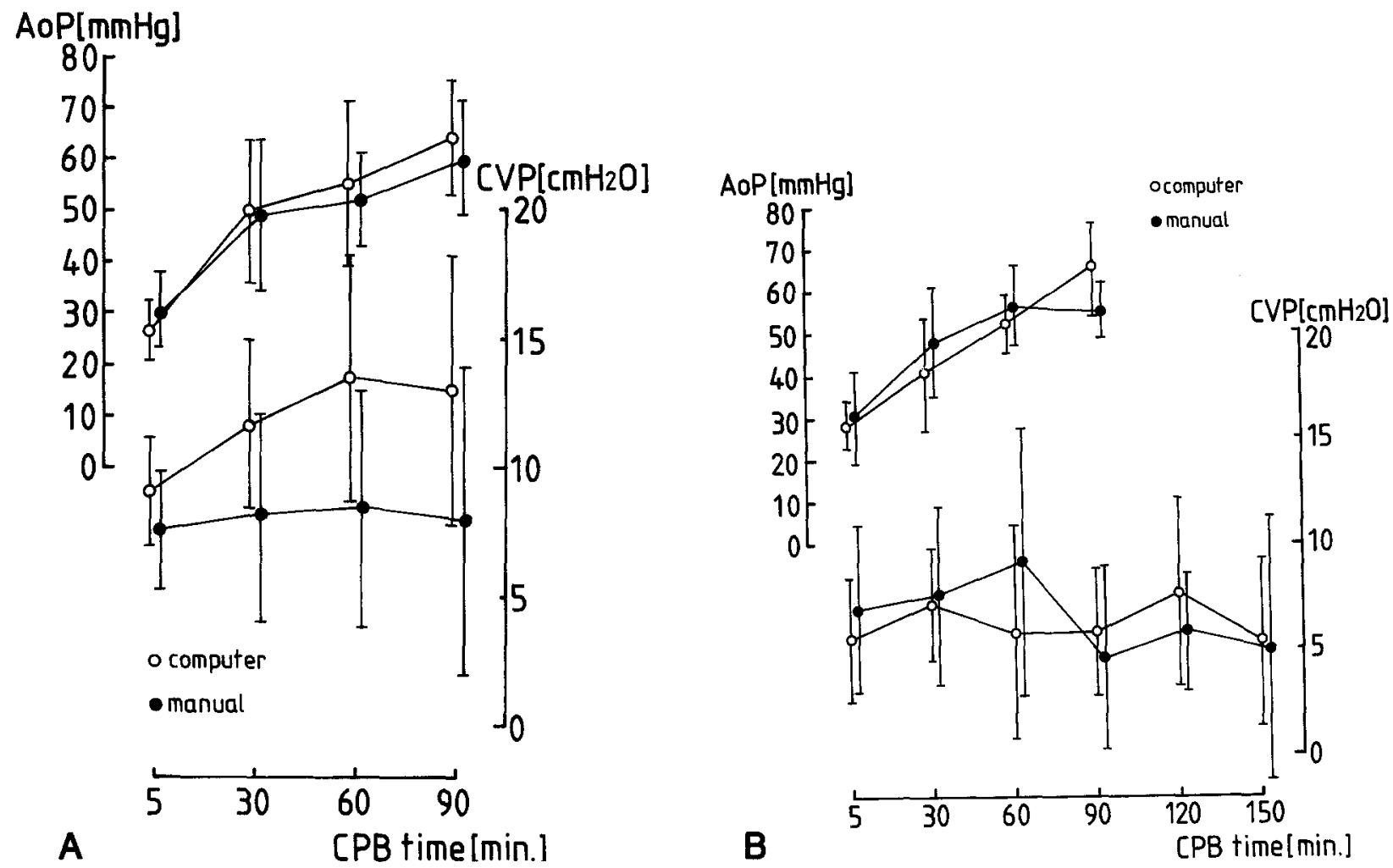

Fig. 6. Mean AoP during aortic crossclamping and mean CVP during CPB. A, Ventricular septal defect. B, Tetralogy of Fallot.

Mean AoP and CVP responses during CPBs were not significantly different (Fig. 6). Mean AoP decreased at the onset of $\mathrm{CPB}$ and gradually rose until the aorta was unclamped. This was the typical response. The CVP measurements were different in each case so that mean value showed no conspicuous change.

\section{Discussion}

We inferred that CVP is an effective reference value for automating CPB. The results of computerized CPB indicated that the total fluid balance of a patient was maintained satisfactorily with the CVP control algorithm. Moreover, the computer automatically responded to several situations of altering the venous withdrawal flow with the CVP control method: the SVC and IVC occlusion stemmed a flow into the right atrium, dissection of the persistent left superior vena cava diminished the caval flow, and a suction or a venting flow decreased the flow through venous cannulas. Consequently, the computer handled a continuous flow difference between the infusion and the withdrawal. However, tilting of the operating table for surgical exposure caused the CVP to shift by reason of changing the relative height between the patient and the pressure transducer. If its shift was larger than about $3 \mathrm{~cm}$ $\mathrm{H}_{2} \mathrm{O}$, the set point value for CVP had to be changed to avoid overtransfusion or the reiterative collapse of venous lines.

AoP was monitored but was not used for a parameter of the automatic control because the systemic blood pressure often was lower in children, owing to the small diameter and the flexible quality of the catheter.

The screening algorithm detected all the catheter flushings, the transducer zero balance checks, and the unintentional touches to the transducer. The algorithm detected the fluctuations caused by surgical manipulation for evacuation of air, yet the computer occasionally resumed its control during manual forced inflation of the lungs. The withdrawal flow rate was not increased, because the inflated lung pressed the venae cavae and stemmed the inlet portion of the venous cannulas in this situation. Because the computer stops adjusting the flow rates while detecting an artifact, a continuous artifact might make computer control impossible. However, 
the longest duration of an artifact was 15 seconds in our clinical experience. So long as the duration of artifacts remained short, they had little influence on the computer control.

On a selected occasion, when drastic changes in reservoir volume were unlikely to happen, the reservoir level control proved to be applicable. However, the reservoir control could not manage CPB from the beginning to the end, because the amount of blood was subjected to numerous changes during $\mathrm{CPB}$, as we denoted on Fig. 3. We tested the reservoir control during total bypass and found that this method required frequent adjustment of the set point value. We therefore limited the application of the reservoir control to the weaning period.

Most of the attempts at automating heart-lung machines were designed to regulate the reservoir blood volume. Mechanisms that adjust the infusion flow rate by the reservoir volume were reported by Kantrowitz, ${ }^{2}$ Lewis, ${ }^{4}$ Andersen, ${ }^{6}$ and Chauveau, ${ }^{7}$ and their associates. The reservoir height adjuster for the same intention was reported by Roche, Ungar, and Coleman. ${ }^{5}$ Anbe and colleagues ${ }^{8}$ used a microcomputer for regulating both systemic blood pressure and the amount of reservoir blood by adjusting the infusion flow rate and the reservoir height. Their system seems to require frequent adjustment of the reservoir volume settings. A device monitoring the subject's weight to adjust the flow rates was reported by Moss. ${ }^{3}$ This method seems to have the same drawback. In addition, the continuous artifacts would be appended to the weight measurement during the operation.

We believe the computerized control system is helpful and improves the safety of CPB. Its control ability was almost equal to that of skillful perfusionists using the conventional method. The control system responded to several situations of altered venous flow, particularly in infants. The control system virtually eliminated the hazard of air embolism or an extremely high CVP. The control system supports us not only in CPB but also in assisted circulation. In addition, the computerized controller can reduce the idle volume in a blood reservoir. The control program can be improved to attain a superior control ability and minimize the CPB circuit to reduce the priming volume. We will use the system for $\mathrm{CPB}$ in neonates.
We gratefully acknowledge Dr. Kiichi Tsuchiya of Department of Machinery Engineering, Waseda University, for his technical advice and Susumu Suzuki, Kazunori Inomata, Shigeki Kamiyashiki, and Yukio Tajima for their excellent technical assistance as perfusionists.

\section{REFERENCES}

1. Gibbon JH. Application of a mechanical heart and lung apparatus to cardiac surgery. In: Recent advances in cardiovascular physiology and surgery. Minneapolis: University of Minnesota, 1953:107-13.

2. Kantrowitz A, Reiner S, Abelson D. An automatically controlled inexpensive pump-oxygenator. J THORAC CARdiovasc Surg 1959;38:586-93.

3. Moss G. A device to maintain automatically and continuously an absolute or relative constant weight of a subject or container during perfusion. Surgery 1961;49:743-4.

4. Lewis FJ, Horwitz SJ, Naines JB. Semiautomatic control for an extracorporeal blood pump. J THORAC CARDiovasc Surg 1962;43:392-6.

5. Roche JJ, Ungar I, Coleman HS. An electrical apparatus for rapid and precise regulation of the venous blood-reservoir height on heart-lung machines. Surgery 1964;56:561-4.

6. Andersen MN, Ulrich JF, Mouritzen CV. An automatic flow control system for extracorporeal circulation. J Thorac Cardiovasc Surg 1965;50:260-4.

7. Chauveau N, van Meurs W, Barthelemy R, Morucci JP. Automatic modules for extracorporeal circulation control. Int J Artif Organs 1990;13:692-6.

8. Anbe J, Nakajima H, Ogura Y, et al. Development of a computer regulated extracorporeal circulation system. Artif Organs Today 1992;2:117-25.

9. Fukui Y, Tsuchiya K, Imai Y. Computer controlled extracorporeal circulation (ECC) with pulsatile perfusion for an infant. Trans Am Soc Artif Intern Organs 1982;28:133-7.

10. Soejima K, Nagase Y, Ishihara K, et al. Computerassisted automatic cardiopulmonary bypass system for infants. In: Atsumi K, ed. Progress in artificial organs-1983. Cleveland: ISAO Press, 1984:918-22.

11. Beppu T, Imai Y, Fukui Y. Computer-controlled cardiopulmonary bypass system. Systems Computers Jpn 1992;23:74-84.

12. Nakata S, Imai Y, Takanashi Y, et al. A new method for the quantitative standardization of cross-sectional areas of the pulmonary arteries in congenital heart diseases with decreased pulmonary blood flow. J Thorac Cardiovasc Surg 1984;88:610-9. 